\title{
PENGARUH BUDAYA ORGANISASI DAN MOTIVASI TERHADAP KINERJA KARYAWAN
}

\author{
Dea Aulia Permatasari \\ Universitas Negeri Surabaya \\ deapermatasari1@mhs.unesa.ac.id
}

\begin{abstract}
The purpose of this study is to examine and analyze the influence of organizational culture and motivation on employee performance at PT. Telkom Indonesia Regional V Surabaya. Quantitative methods are used to obtain data by returning questionnaires that have been filled out by employees. In this study, the sample used was 80 people from a total population of 168 people. The sample is taken from each unit at PT. Telkom Indonesia Regional V Surabaya. Data analysis is Structural Equation Modeling (SEM) with PLS (Partial Least Square) approach using Smart PLS software. The results of this study indicate that the influence of organizational culture has a positive and significant effect on employee performance, and motivation has a positive and significant effect on employee performance.
\end{abstract}

Keywords: employee performance; motivation; organizational culture.

\section{PENDAHULUAN}

Dunia telekomunikasi kini mengalami pertumbuhan yang semakin pesat. Perusahaan yang mengalami dampak dari perkembangan Teknologi Informasi dan Komunikasi (TIK) yakni PT. Telekomunikasi Indonesia perusahaan yang bergerak pada layanan jasa penyedia telekomunikasi. Baik masyarakat perkotaan maupun perdesaan menggunakan jasa layanan telekomunikasi untuk melakukan aktivitas sehari-harinya. Komunikasi dua arah melalui jarak jauh dengan tujuan pertukaran infomasi antar individu merupakan layanan dari telekomunikasi (Utami, 2017).

Peran sumber daya manusia sangat penting bagi PT. Telkom Indonesia sehingga pengelolaannya perlu dilakukan secara maksimal. Hal tersebut dapat berdampak pada meningkatnya kualitas produk dan layanan perusahaan. Faktor yang berpengaruh terhadap kedudukan peningkatan sumber daya manusia yaitu budaya organisasi dan motivasi kerja. Semakin berkembangnya perindustrian dibidang telekomunikasi baik dalam negeri ataupun tingkat global menjadi tantangan tersendiri pada sebuah perusahaan. PT. Telkom Indonesia berniat melakukan perubahan secara mendasar dan merata di seantero taraf bisnis yaitu meliputi transformasi bisnis dan portofolio, transformasi prasarana dan sistem, organisasi dan sumber daya manusia, serta budaya organisasi yang dimiliki perusahaan (Sakti \& Arwiyah, 2012).

Budaya organisasi sendiri memiliki sebutan budaya kerja, disebabkan karena budaya organisasi tidak dapat terlepas dari kinerja sumber daya manusia. Semakin berpengaruh budaya perusahaan, maka semakin kuat keinginan agar dapat mengahasilkan hasil kerja yang baik. Secara tegas budaya organisasi perusahaan sulit diartikan dan sulit juga untuk diukur, akan tetapi hal ini dapat dirasakan oleh sumber daya manusia dalam sebuah perusahaan. Oleh sebab itu sebuah organisasi akan terbentuk dari suatu kumpulan individu yang berlainan baik sifat, keunikan, kemahiran, pendidikan, pengalaman, serta latar belakang. Sehingga sangat diperlukan adanya pengakuan yang bermanfaat guna meraih visi misi organisasi agar dapat berjalan beriringan (Aditama, 2020).

Selain budaya organisasi terdapat variabel yang bisa memengaruhi yaitu motivasi. Motivasi sangat berpengaruh pada kinerja seorang karyawan, karena motivasi ialah daya yang mampu menggerakkan seorang karyawan dalam menyelesaikan tugas yang diberi atasan. Pekerjaan tersebut bertujuan untuk mencapai tujuan perusahaan. Suatu organisasi dikatakan sederhana dan akan menjadi masalah yang kompleks, apabila setiap individu diberikan motivasi berupa sesuai dengan keinginannya. Permasalahan dalam motivasi bisa menjadi kompleks saat memilih kompensasi, di mana hal yang diduga bernilai bagi suatu individu belum pasti bernilai juga bagi individu yang lain (Wijaya, 2018). 
Dea Aulia Permatasari. Pengaruh Budaya Organisasi dan Motivasi terhadap Kinerja Karyawan PT. Telkom Indonesia Regional V Surabaya

Adanya motivasi perusahaan terhadap karyawan dapat mengahasilkan manfaat untuk perusahaan dalam mencapai harapan yang diinginkan. Motivasi yang berkesinambungan bisa memberikan efek positif dalam mendukung tingkat kinerja karyawan (Arimbawa \& Dewi, 2013).

Kinerja sendiri adalah gabungan dari tiga faktor-faktor pokok antara lain yaitu kapasitas dan kecenderungan pekerja, kesanggupan dan penerimaan mengenai penjelasan mandat tugas, juga peran dan kualitas motivasi seorang karyawan (Hasibuan, 2006). Maka untuk mengetahui tingkat keberhasilan pencapaian visi yang dimiliki perusahaan dalam jangka waktu tertentu, penilaian kinerja sumber daya manusia menjadi peting untuk dilakukan (Nadhira \& Rustono, 2018).

Penelitian bertujuan untuk menganalisis mengenai pengaruh budaya organisasi terhadap kinerja karyawan, dan pengaruh motivasi terhadap kinerja karyawan.

\section{KAJIAN PUSTAKA DAN PENGEMBANGAN HIPOTESIS}

\section{Budaya Organisasi}

Secara umum budaya organisasi merupakan suatu karakteristik pada organisasi yang menjadi acuan organisasi untuk menjadi pembanding suatu organisasi dengan organisasi yang lainnya (Rahmawati, 2020). Menurut Mariati (2018), budaya organisasi harus dapat diajarkan kepada anggota baik anggota baru ataupun lama untuk memiliki persepsi sama yang dimiliki oleh anggota dari organisasi. Dibutuhkan konsistensi panjang dalam jangka panjang yang terkait pada penerapan tindakan dan nilai yang dianggap penting dalam organisasi. Budaya organisasi merupakan nilai yang digunakan untuk menjadi acuan dan digunakan suatu individu atau organisasi untuk memecahkan setiap masalah, sebagai usaha untuk beradaptasi saat bergabung dalam suatu lembaga sehingga pada setiap hal yang menjadi acuan perilaku dapat diketahui dan dipahami oleh anggota organisasi (Erwantiningsih, 2019).

Sedangkan Sriekaningsih \& Setyadi (2015) menjelaskan bahwa budaya organisasi ialah sistem penjelasan bersama yang dipegang oleh anggota yang membedakan organisasi dari organisasi lain. Sistem uraian universal ini yakni seperangkat kunci ciri yang dijunjung besar oleh organisasi. Elemen budaya sangat bernilai dalam pengembangan sesuatu organisasi, budaya organisasi terdiri dari hal- hal yang tidak kasat mata serta hal- hal abstrak semacam nilai, norma, sikap, serta menggambarkan inti dari anggapan sangat mendasar. Budaya organisasi dapat memaksimalkan keahlian karyawan secara terus- menerus, hingga kelangsungan hidup organisasi akan bertahan lama, apabila tidak, budaya juga bisa bawa pengaruh kurang baik pada organisasi, yang jadi kontraproduktif terhadap upaya manajemen dalam menaikkan prestasi (Kusworo, Armanu, Rahayu, 2015).

Budaya organisasi menunjang menciptakan rasa memiliki terhadap organisasi, menghasilkan keterikatan emosional antara organisasi serta karyawan yang ikut serta di dalamnya, menunjang menghasilkan stabilitas organisasi sebagai sistem sosial serta menciptakan pola pedoman prilaku sebagai hasil dari norma-norma kerutinan yang tercipta dalam keseharian (Sulastri, 2017). Menurut Purba \& Gunawan (2018), budaya organisasi merupakan nilai nilai, norma, bukti diri, serta sistem yang mengikat serta memastikan sikap tiap karyawan di industri. Tidak hanya nilai, budaya organisasi pula bisa digunakan sebagai bukti diri yang membedakan organisasi dari organisasi lain sehingga memberikan citra merk suatu organisasi.

\section{Motivasi}

Motivasi ialah kekuatan yang dapat menjadi pendorong individu dalam mengambil tindakan yang tidak pada hakikatnya dengan internal dan eksternal sehingga menghasilkan dampak positif atau sebaliknya negatif untuk menepatkan yang terkait pada ketangkasan seorang pimpinan (Ardana, 2012). Menurut Zameer et al. (2014), motivasi karyawan tebentuk dari proses di mana suatu organisasi dapat memengaruhi pekerja dengan cara memberi hadiah, penghargaan, dll. dalam menggapai suatu misi organisasi. Mariati (2018) menyatakan bahwa motivasi mengarahkan kekuatan serta kemampuan karyawan untuk dapat berpartisipasi dengan produktif, sehingga mampu merealisasikan serta mencapai tujuan yang diterapkan. 
Menurut Purba \& Gunawan (2018), motivasi merupakan dorongan yang membuat karyawan berperilaku dan tertarik dalam melaksanakan pekerjaan dengan optimal ataupun maksimal buat menggapai tujuan tertentu. Dalam motivasi terdapat elemen yang mencakup dorongan, kebangkitan memusatkan serta mempertahankan keseriusan seorang buat melakukan kinerja. Kinerja karyawan dapat dipengaruhi oleh keterampilan, pengaturan kerja serta motivasi, karena kreativitas tidak dapat diterapkan di perusahaan tanpa adanya keterlibatan karyawan (Liu, 2013).

Sedangkan menurut Erwantiningsih (2019), motivasi ialah tenaga dari dalam serta luar yang mendesak manusia untuk mencapai harapan serta tujuan yang sudah didetetapkan ataupun motivasi dapat pula memiliki makna sebagai proses gimana orang lain ataupun karyawannya dapat dipengaruhi untuk beraktifitas dan menuntaskan tugasnya sesuai penetapan tujuan yang sudah dibuat sebelumnya.Maka dari itu perihal yang mendasar sebagai uraian proses motivasi terdapat pada ikatan antara dorongan, kemauan, serta insentif.

\section{Kinerja Karyawan}

Kinerja yaitu pembanding antara standar kerja yang ditetapkan dengan hasil yang nyata (Simamora, 2006). Berdasarkan penelitian Subagiono (2011) kinerja ialah mutu dan kapasitas dari hasil kerja individu atau kelompok dalam sebuah aktifitas atau dalam suatu periode. Menurut Erwantiningsih (2019), kinerja adalah hasil kerja yang teramati sebagai prestasi kerja karyawan baik secara mutu dalam jumlah yang sama dengan kriteria kerja, beban kerja yang telah diberikan, dan disesuaikan dengan target yang diharapkan untuk meraih meraih tujuan organisais pada waktu yang ditetapkan.

Kinerja karyawan akan tercapai apabila karyawan tersebut mempunyai motivasi untuk bekerja. Motivasi kerja ini hendak tercapai bila terdapat keinginan dari dirinya sendiri serta menemukan dorongan dari pihak lain (Riupassa, 2018). Menurut Sulastri (2017), kinerja ialah perwujudan kerja yang dilakukan oleh karyawan yang umumnya dipakai sebagai dasar evaluasi terhadap karyawan ataupun organisasi, sehingga butuh diupayakan untuk menaikkan kinerja.

Sedangkan menurut Purba \& Gunawan (2018), kinerja merupakan deskripsi sejauh mana keberhasilan ataupun kegagalan organisasi dalam melakukan operasinya untuk menggapai sasaran, tujuan, tujuan, visi, serta misi organisasi. Tidak hanya itu, kinerja pula berarti mutu serta kuantitas kerja ataupun kelompok orang untuk menggapai tujuan tertentu.

\section{Hubungan antar Variabel}

Uddin et al., (2012) membuktikan bahwa berbagai atribut budaya organisasi berdampak positif serta memiliki dampak signifikan terhadap kinerja organisasi. Penelitian tersebut telah memetakan aspek budaya yang berbeda dari organisasi serta menunjukkan hubungan penting antara kinerja dengan budaya.

H1: Diduga budaya organisasi memiliki dampak positif dan signifikan terhadap kinerja karyawan PT. Telkom Indonesia Regional V Surabaya.

Motivasi dan kinerja karayawan mempunyai koneksi yang positif hal tersebut dikarenakan apabila seorang karyawan mempunyai motivasi yang tinggi maka karyawan tersebut akan memiliki kinerja yang juga tinggi (Armstrong, 2009). Sehingga bertambah tingginya motivasi kerja maka kinerja karyawan juga akan kian tinggi. Setiap individu berusaha bekerja semaksimal mungkin agar dapat memenuhi kebutuhan hidup sehingga dapat mencapai tujuan yang sudah ditargetkan. Menurut penelitian Kusworo, Armanu, Rahayu, (2015) motivasi berpengaruh signifikan dalam meningkatkan kinerja pendidik.

H2: Diduga motivasi memiliki dampak positif dan signifikan terhadap kinerja karyawa PT. Telkom Indonesia Regional V Surabaya. 
Dea Aulia Permatasari. Pengaruh Budaya Organisasi dan Motivasi terhadap Kinerja Karyawan PT. Telkom Indonesia Regional V Surabaya

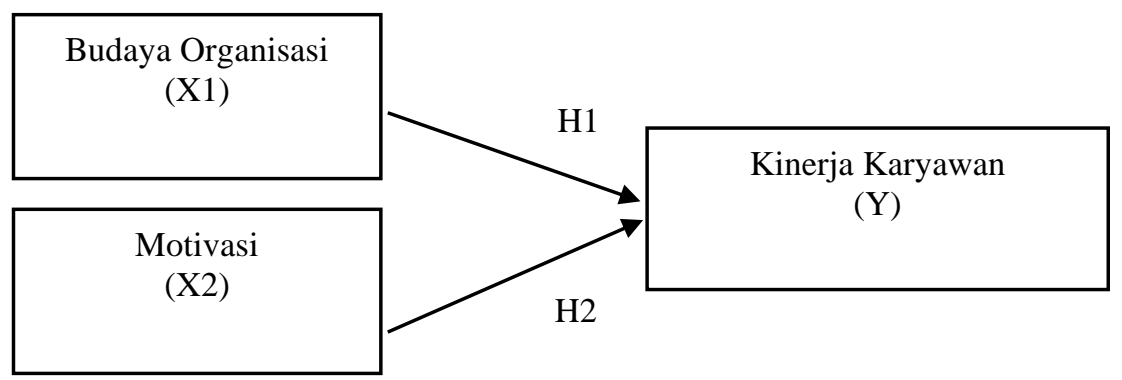

\section{Gambar 1. KERANGKA KONSEPTUAL}

\section{METODE PENELITIAN}

Jenis penelitian ini merupakan penelitian kuantitatif dengan menggunakan data primer. Pengumpulan data tersebut dilakukan memakai metode observasi, wawancara, dan kuesioner. Studi kasus pada pengkajian ini dilakukan di PT. Telkom Indonesia Regional V Surabaya. Pada penelitian yang dilakukan pengambilan sampel tersebut menggunakan metode probability sampling yang merupakan stratified random sampling untuk memisahkan bagian-bagian populasi dalam golongan yang tidak tumpang tindih atau sering disebut strata, kemudian sampel diambil secara acak setiap masing-masing tingkatan divisi dalam perusahaan. Data diolah dengan Analisis Structural Equation Modeling (SEM) yakni metode pendekatan preferensi PLS (Partial Least Square) dengan software Smart PLS.

\section{HASIL DAN PEMBAHASAN}

\section{Hasil Analisis Statistik Inferensial}

Indikator dalam kuesioner penelitian ini telah menghasilkan nilai yang valid. Hasil tersebut terlihat dari angka outer loading $>0,50$. Model konstruk dikatakan valid jika seluruh indikator memenuhi syarat dari convergent validity. Convergent Validity dalam parameter dapat dinyatakan valid atau tidak dapat terlihat pada nilai loading faktor yang terdapat pada tiap indikator. Indikator dapat valid apabila korelasinya $>0,70$. Tetapi, pada penilaian tahap awal jika nilai loading memiliki nilai 0,50 hingga 0,60 sudah dianggap cukup memenuhi syarat (Ghozali, 2014). Gambar 2 menunjukkan hasil uji measurement model.

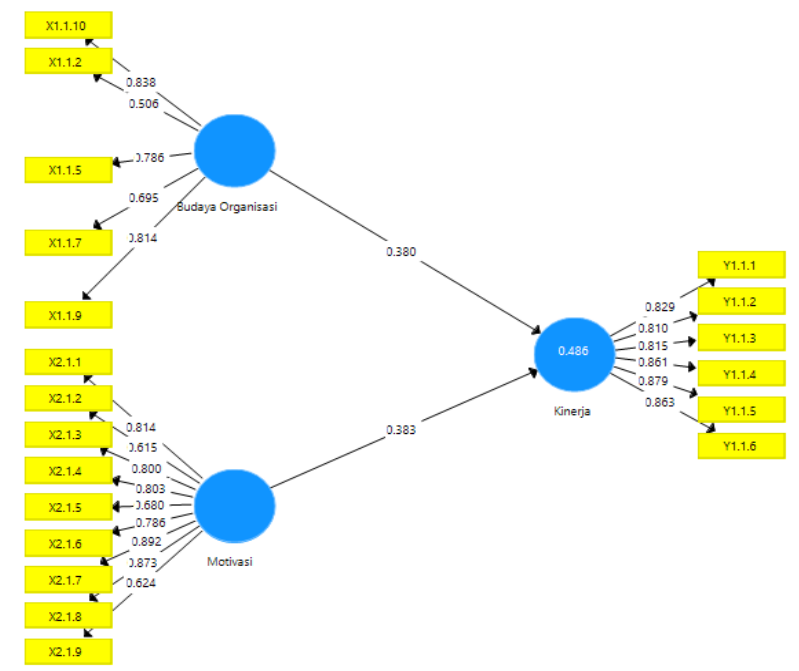

Sumber: Output Smart PLS (2020)

Gambar 2. UJI MEASUREMENT MODEL

Gambar 2 merupakan olah data uji measurement model. Nilai loading yang dimiliki oleh tiap indikator dari ketiga variabel lebih dari 0,5 sehingga bisa dinyatakan indikator yang digunakan telah valid. 


\section{Discriminant Validity}

Pada uji discriminant validity dapat diperoleh melalui skala akar Average Variance Extracted (AVE) untuk masing-masing konstruks dapat dibandingkan dengan korelasi antar konstruk. Perbedaan hasil nilai AVE dapat dilihat dari korelasi antar variabel yang tertera pada tabel 1 .

Tabel 1

HASIL AVERAGE VARIANCE EXTRAC (AVE)

\begin{tabular}{ccc}
\hline Variabel & $\boldsymbol{A} \boldsymbol{V E}$ & Akar AVE \\
\hline Budaya Organisasi (X1) & 0,544 & 0,783 \\
Motivasi (X2) & 0,595 & 0,771 \\
Kinerja Karyawan (Y) & 0,711 & 0,843 \\
\hline
\end{tabular}

Sumber: Data diolah (2020)

Tabel 2

NILAI KORELASI ANTAR VARIABEL

\begin{tabular}{lccc}
\hline \multicolumn{1}{c}{ Variabel } & Budaya Organisasi & Kinerja Karyawan & Motivasi \\
\hline Budaya Organisasi & 0,738 & & \\
Kinerja Karyawan & 0,637 & 0,843 & \\
Motivasi & 0,671 & 0,638 & 0,771 \\
\hline
\end{tabular}

Sumber: Data diolah (2020)

Bisa dilihat pada tabel 1 dan 2 menunjukan nilai akar AVE dalam seluruh konstruk memiliki nilai tinggi dibandingkan dengan nilai-nilai korelasi antar konstruk yang lainnya. Sehingga berdasarkan nilai yang dihasilkan dapat didefinisikan dengan kesimpulan bahwa semua konstruk mempunyai discriminat validity yang baik.

\section{Composite Reliability}

Pada composite reliability berfungsi dalam menguji nilai reliability antara variabel indikator dan konstruk dalam variabel. Variabel dapat dinyatakan reliability dan memiliki dampak positif apabila nilai pada composite reliability $>0,70$.

\section{Cronbach's Alpha}

Hasil reliability dapat diperkuat dengan angka cronbach's alpha dari composite reliability. Sebuah variabel dinyatakan reliable jika nilai croncbach's alpha $>0,60$. Nilai tersebut memiliki realibility yang baik karena telah memenuhi nilai persyaratannya. Seluruh variabel dapat dinyatakan telah memiliki tingkat reliability yang tinggi jika cronbach's alpha tinggi.

\section{Analisis R-Square}

Pada analisis uji $R$-square ini merupakan uji yang digunakan dalam menentukan seberapa besar inner model yang dibentuk. Hasil dari output dari SmartPLS 3.0. yang diolah oleh penulis menghasilkan nilai uji $r$-square 0,486 . Artinya, budaya organisasi serta motivasi memiliki efek terhadap kinerja karyawan sebesar $48,6 \%$, sedangkan sisanya sebesar $51,4 \%$ selisih yang berpengaruh oleh faktor lain diluar model yang memiliki efek terhadap kinerja karyawan PT. Telkom Indonesia Regional V, Surabaya.

\section{Uji Kasualitas}

Inner model dilakukan untuk mengetahui korelasi antara konstruk dengan nillai signifikan pada path coefficient dan hasil indirect effects seperti tertulis di Tabel 3. Berdasarkan tabel 3 dilihat besarnya nilai $t$-statitic pengaruh budaya organisasi kepada kinerja 3,417 di mana nilai tersebut $>1,96$. Hasil menunjukan bahwa variabel budaya organisasi pada kinerja karyawan mempunyai efek signifikan kepada kinerja karyawan. Sedangkan koefisien estimate memiliki nilai positif sebesar 0,380 yang 
Dea Aulia Permatasari. Pengaruh Budaya Organisasi dan Motivasi terhadap Kinerja Karyawan PT. Telkom Indonesia Regional V Surabaya

berarti semakin meningkat budaya organisasi yang ada maka semakin meningkat pula kinerja tersebut. Nilai terbilang memiliki nilai positif karena menggambarkan makna yang berbanding lurus.

\section{Tabel 3 \\ HASIL PATH COEFFICIENT}

\begin{tabular}{lcccc}
\hline \multicolumn{1}{c}{ Pengaruh antar Variabel } & Original Sample & T-Statistics & \multicolumn{2}{c}{ Keterangan } \\
\hline $\begin{array}{l}\text { Budaya Organisasi } \rightarrow \text { Kinerja } \\
\text { Karyawan }\end{array}$ & 0,380 & 3,417 & $\geq 1,96$ & Hipotesis \\
Motivasi $\rightarrow$ Kinerja Karyawan & 0,383 & & $($ Signifikan) & Diterima \\
& & 3,669 & $\geq 1,96$ & Hipotesis \\
& & & (Signifikan) & Diterima \\
\hline
\end{tabular}

Sumber: Output SmartPLS 3.0 (2020)

\section{Pengaruh Budaya Organisasi terhadap Kinerja Karyawan PT. Telkom Indonesia Regional V Surabaya}

Berlandaskan hasil penelitian yang dilakukan dapat diketahui bahwa budaya organisasi memiliki dampak pada kinerja karyawan. Hal tersebut dapat diketahui berdasarkan hasil $t$-statistic yang bernilai lebih besar dari nilai signifikan sehingga terima H1. Sedangkan nilai koefisien estimate pada penelitian ini memiliki nilai yang tergolong tinggi dan memiliki arah positif. Hal tersebut dapat diartikan jika budaya organisasi tinggi maka kinerja karyawan juga akan semakin meningkat, hal itu dikarenakan makna positif yang berarti berbanding lurus. Hasil ini sesuai dengan kondisi di tempat penelitian di mana penerapan budaya organisasi salah satunya budaya kolaborasi yaitu bekerja sama atau kolaborasi antar unit dan lintas generasi dalam menyelesaikan tugas yang diberikan, dapat meningkatkan kinerja karyawan PT. Telkom Indonesia Regional V Surabaya. Selain itu perusahaan juga memfasilitasi karyawan dengan mengadakan workshop mengenai budaya oganisasi perusahan. Seperti workshop "Generation Diversiy in Workplace" untuk memahamkan dan mendorong karyawan dalam penerapan budaya kolaborasi.

Hasil penelitian ini sejalan dengan riset Erwantiningsih (2019). Dengan indeks yang sama, dalam hasil riset tersebut menunjukan dalam budaya organisasi terdapat dampak positif yang memengaruhi kinerja karyawan, di mana individu jika memiliki budaya organisasi yang tinggi berarti dapat menerapkan budaya organisasi tersebut dalam bekerja. Penelitian Purba \& Gunawan (2018), juga menunjukan hasil yang sama. Meskipun hanya menggunakan lima indikator saja yaitu innovation on risk, orientation in result, orientation on people, orientation on team, and aggressiveness, penelitian tersebut menunjukan hasil yang sama. Nilai $t$-statistic budaya organisasi pada penelitian Purba \& Gunawan, (2018) yaitu memiliki nilai yang termasuk dalam kategori sedang. Sedangkan dalam penelitian ini nilai t-statistic tergolong tinggi. Hal ini menunjukan bahwa meski memiliki hasil yang sama, indikator yang digunakan dapat merubah tinggi rendahnya pengaruh terhadap budaya organisasi pada kinerja karyawan. Jika semakin banyak indikator yang sesuai yang digunakan dalam penelitian, hasilnya akan semakin baik.

Berbeda dengan hasil penelitian di atas yang menunjukan bahwa budaya organisasi berpengaruh positif dan signifikan terhadap kinerja, hasil yang berbeda ditunjukan dalam penelitian yang dilakukan oleh Maabuat, (2016). Menurut Maabuat, (2016) budaya organisasi bernilai negatif dan tidak bepengaruh signifikan terhadap kinerja karyawan. Hal ini dapat di lihat dari hasil koefisien regresi yaitu dengan nilai signifikansi yang lebih besar.

\section{Pengaruh Motivasi terhadap Kinerja Karyawan PT. Telkom Indonesia Regional V Surabaya}

Pada hasil pengujian menunjukkan motivasi berpengaruh pada kinerja karyawan. Hal tersebut diketahui angka t-statistic yang bernilai lebih besar dari nilai signifikan sehingga terima H2. Hasil penelitian ini juga menerangkan motivasi berdampak positif pada kinerja karyawan dan berpengaruh signifikan, terlihat pada angka koefisien estimate yang tergolong tinggi. Angka ini dapat diartikan apabila motivasi tinggi maka kinerja karyawan juga akan semakin meningkat, hal ini menghasilkan makna positif berbanding lurus. Berdasarkan hasil yang didapatkan maka ditarik kesimpulan yaitu tingginya motivasi kerja karyawan PT. Telkom Indonesia Regional V Surabaya dapat memberikan 
peningkatan pada kinerja karyawan. Hal ini sesuai dengan kondisi dilapangan di mana PT. Telkom Indonesia Regional V Surabaya telah memberikan motivasi kerja pada kayawan berupa penghargaan dengan memberikan hadiah atau insentif yang setimpal dengan prestasi yang diraih, menerapkan program staff on the month, serta memberikan pelatihan-pelatihan. Motivasi yang diberikan tersebut telah berdampak pada meningkatnya kinerja karayawan, hal ini ditunjukan dari data perusahaan mengenai nilai kinerja pegawai PT. Telkom Indonesia Regional V Surabaya yang meningkat setiap tahunnya.

Hasil yang sama dengan riset yang dilakukan Zameer et al., (2014), di mana motivasi memiliki kedudukan penting dalam organisasi baik publik dan swasta. Apabila tidak ada motivasi terhadap karyawan maka karyawan tidak bisa bekerja secara maksimal juga tidak bisa meraih tujuan dari kinerja karyawan. Hal yang sama ditunjukan oleh pengkajian yang dilakukan Uddin et al., (2012). Uddin et al., (2012) mengatakan kedudukan departemen sumber daya manusia sangat penting dalam memengaruhi budaya organisasi. Kinerja karyawan yang dipertahankan dan penyelewengan melalui motivasi, penghargaan, dan kode etik. Rapat yang dilakukan setiap pekan dan diskusi terbuka terjadi di organisasi mencegah adanya konflik, meningkatkan budaya organisasi dan mempromosikan pembelajaran terbuka.

Berbeda dengan hasil penelitian di atas yang menunjukan bahwa motivasi berpengaruh positif dan signifikan terhadap kinerja, hasil yang berbeda ditunjukan dalam penelitian yang dilakukan oleh Sulastri, (2017) mengatakan bahwa motivasi tidak memiliki pengaruh signifikan terhadap kineja karyawan. Hal ini ditunjukan dari nilai t-statistik tergolong rendah yang lebih kecil dari nilai t-tabel.

\section{KESIMPULAN}

Berlandaskan penelitian yang dilakukan maka memiliki kesimpulan bahwa variabel budaya organisasi berpengaruh positif dan signifikan pada kinerja karyawan PT. Telkom Indonesia Regional V Surabaya. Hal ini dapat diartikan jika budaya organisasi meningkat maka kinerja karyawan juga akan ikut tinggi begitu pun sebaliknya. Sama halnya variabel motivasi, yang berpengaruh positif serta memiliki dampak pada kinerja pegawai di PT. Telkom Indonesia Regional V Surabaya. Hal tersebut dapat diartikan jika motivasi kerja mengalami peningkatan maka kinerja karyawan juga akan ikut meningkat begitu juga sebaliknya.

Penerapan budaya organisasi di PT. Telkom Indonesia Regional V Surabaya memiliki nilai yang baik, tetapi masih ada beberapa karyawan belum menerapkan nilai dalam budaya organisasi. Maka perlu diadakan pengontrolan dan motivasi dari manager perusahaan agar karyawan senantiasa menerapkan nilai-nilai budaya organisasi perusahaan demi teraihnya kinerja karyawan yang sesuai dengan target maksimalnya. Pada penelitian selanjutnya dapat dikembangkan dengan melibatkan variabel lain yang memiliki keterkaitan dengan kinerja karyawan seperti lingkungan kerja dan kompensasi.

\section{DAFTAR PUSTAKA}

Aditama, R. A. (2020). Pengantar Manajemen: Teori dan Aplikasi. AE Publishing.

Ardana. (2012). Manajemen Sumber Daya Manusia. Graha Ilmu.

Arimbawa, K., \& Dewi, A. (2013). Pengaruh Budaya Organisasi, Gaya Kepemimpinan, Dan Motivasi Kerja Terhadap Kinerja Karyawan Pada Hotel Jimbaran Puri Bali. E-Jurnal Manajemen Universitas Udayana, 2(12), 247931.

Armstrong, M. (2009). Armstrong's Handbook of Human Resource Management Practice (11 th Ed.). London: Kogan Page.

Erwantiningsih, E. (2019). Pengaruh Motivasi, Komunikasi dan Budaya Organisasi terhadap Kinerja 
Dea Aulia Permatasari. Pengaruh Budaya Organisasi dan Motivasi terhadap Kinerja Karyawan PT. Telkom Indonesia Regional V Surabaya

Karyawan. Jurnal Manajemen Dan Kewirausahaan, 7(2). https://doi.org/doi: 10.26905/jmdk.v7i2.3247

Ghozali, I. (2014). Structur Equation Modeling: Motode Alternatif dengan Partial Least Square (PLS) (4 th ed). Badan Penerbit Universitas Diponogoro.

Hasibuan, M. S. . (2006). Manajemen Dasar, Pengertian dan Masalah (Edisi Revi). Bumi Aksara.

Kusworo, Armanu, Rahayu, S. (2015). Influence of Motivation, Organizational Culture and Working Environment With Organizational Commitment As Mediator To Educator Performance. The International Journal of Social Sciences, 35(1), 1-15.

Liu, C. H. (2013). The processes of social capital and employee creativity: Empirical evidence from intraorganizational networks. In International Journal of Human Resource Management (Vol. 24, Issue 20, pp. 3886-3902). Taylor \& Francis. https://doi.org/10.1080/09585192.2013.781519

Maabuat, E. S. (2016). Pengaruh Kepemimpinan, Orientasi Kerja, dan Budaya Organisasi Terhadap Kinerja Pegawai (Studi Pada Dispenda Sulut UPTD Tondano). Jurnal Berkala Ilmiah Efisiensi, 16(01), 219-231.

Mariati. Mauludin Hanif. (2018). The Influence of Organizational Culture And Work Motivation on Employee Performance, Job Satisfaction As Intervening Variable ( Study On Secretariat Staff of Pasuruan Regency ). 20(8), 30-39. https://doi.org/10.9790/487X-2008013039

Nadhira Rahma Siti, \& Rustono Anthon. (2018). Pengaruh Budaya Organisasi Terhadap Kinerja Karyawan (Studi Kasus Pada PT Telekomunikasi Indonesia Witel Jakarta Selatan Unit HR\&amp;CDC dan Network Area). 5(1), 260-267.

Purba, C. B., \& Gunawan, P. N. (2018). The Influence of Work Motivation, Organizational Culture and Career Development on Employee Performance in PT. Titis Sampurna Inspection. Saudi Journal of Business and Management Studies (SJBMS), 3(6), 629-640. https://doi.org/10.21276/sjbms.2018.3.6.4

Rahmawati, L. (2020). Pengaruh Budaya Organisasi dan Motivasi terhadap Kinerja Pegawai (Studi Kasus Kantor Camat Lubuk Begalung Kota Padang). https://doi.org/10.31219/osf.io/7he48

Riupassa, E. (2018). The Influence of Organizational Culture and Work Motivation. RJOAS, 9(81), September 2018, 9(81), 88-95.

Sakti, L. B., \& Arwiyah, M. Y. (2012). Pengaruh Budaya Organisasi dan Kepuasan Kerja terhadap Kinerja Karyawan Telkom Direktorat Human Capital And General Affairs. Tugas Akhir. Bandung: Manajemen Bisnis Telekomunikasi \& Informatika Telkom University.

Simamora, H. (2006). Manajemen Sumber Daya Manusia. Sekolah Tinggi Ilmu Ekonomi YKPN.

Sriekaningsih, A., \& Setyadi, D. (2015). The Effect Of Competence And Motivation And Cultural Organization Towards Organizational Commitment And Performance On State University Lecturers In East Kalimantan Indonesia. European Journal of Business and Management, 7(17), 208-219.

Sulastri, E. S. G. dan T. (2017). Pengaruh Budaya Organisasi , Motivasi , Dan Kepuasan Kerja Terhadap Kinerja Karyawan PT . PLN ( Persero ) Wilayah Kalimantan Selatan dan Kalimantan. Jurnal Bisnis Dan Pembangunan, 6(1). 
Uddin, M. J., Luva, R. H., \& Hossain, S. M. M. (2012). Impact of Organizational Culture on Employee Performance and Productivity: A Case Study of Telecommunication Sector in Bangladesh. International Journal of Business and Management, 8(2), 63-77. https://doi.org/10.5539/ijbm.v8n2p63

Utami, G. S. S. (2017). Studi Deskriptif Budaya Organisai PT. Telekomunikasi Indonesia Wilayah Telekomunikasi Solo. Unika Soegijapranata Semarang.

Wijaya, A. J. (2018). ( Studi Pada Karyawan PT . Ika Jaya Sahara Karya Malang ). 60(1), 180-186.

Yoyok Hari Subagiono. (2011). Pengaruh Budaya Organisasi dan Motivasi Kerja terhadap Kinerja Guru. Jurnal JIBEKA, 9(16), 65-80.

Zameer, H., Alireza, S., NISAR, W., \& AMIR, M. (2014). The Impact of the Motivation on the Employeeâ $\square \mathrm{TM}_{\mathrm{S}}$ Performance in Beverage Industry of Pakistan. International Journal of Academic Research in Accounting, Finance and Management Sciences, 4(1), 293-298. https://doi.org/10.6007/ijarafms/v4-i1/630 